\title{
Impact of US Uncertainties on Emerging and Mature Markets: Evidence from a Quantile-Vector Autoregressive Approach ${ }^{\#}$
}

\author{
Helena Chuliá, Rangan Gupta ${ }^{* *}$, Jorge M. Uribe ${ }^{* * *}$ and Mark E. Wohar ${ }^{* * * *}$
}

\begin{abstract}
In the wake of the recent financial crisis, a growing literature measures, and analyses the impact of uncertainty on international financial markets. These studies are primarily based on conditional mean-based models. Quantile models can be employed to capture the heavy-tails of stock returns, however, they are limited to causal relationships, and hence are silent about the sign and persistence of any uncertainty shocks - both of which are important information for investors. Our paper is the first to employ quantile impulse-response functions obtained from multivariate quantile models to analyze the impact of US policy and US equity market uncertainties on not only domestic stock returns, but also stock returns of mature and emerging markets. Using daily data over the period January 1998 to March 2016, we find that during episodes of financial distress, an uncertainty shock reduces stock market returns; both in mature and emerging markets, but in higher magnitudes for the latter, while it increases the highest quantiles of returns, only for the mature markets. Policy uncertainty is a less relevant factor, but it still impacts negatively the stock market dynamics during episodes of financial distress, especially for the emerging markets. These results contrast with the market reactions to uncertainty in the median scenarios, which tend to be insignificant in all the cases.
\end{abstract}

JEL Codes: C32; G10.

Keywords: Economic Policy and Equity Market Uncertainties; Emerging and Mature Stock Markets; Quantile Vector Autoregressive Model.

\footnotetext{
\# We would like to thank an anonymous referee for many helpful comments. However, any remaining errors are solely ours.

* Riskcenter- IREA and Department of Econometrics, Universitat de Barcelona, Av. Diagonal, 690, 08034. Barcelona, Spain. Email: hchulia@ub.edu.

** Department of Economics, University of Pretoria, Pretoria, 0002, South Africa. Email: rangan.gupta@up.ac.za.

**** Department of Economics, Universidad del Valle, Calle 13, \#100-00, Ciudadela Universitaria Melendez, Cali, Colombia. Email: jorge.uribe@,correounivalle.edu.co.

**** Corresponding author. College of Business Administration, University of Nebraska at Omaha, 6708 Pine Street, Omaha, NE 68182, USA, and School of Business and Economics, Loughborough University, Leicestershire, LE11 3TU, UK. Email: mwohar@,unomaha.edu.
} 


\section{Introduction}

The importance of uncertainty for financial markets and the economy in general, based on theoretical models, has been well recognized as far back as the works of Bernanke (1983), and Dixit and Pindyck (1994), and more recently, Bloom (2009). However, in the wake of the recent financial crisis, a voluminous and growing international literature has emerged, which has attempted to provide empirical estimates of the size of the effect of uncertainty on financial markets (see for example, Bloom (2009), Sum (2012a, b, forthcoming), Antonakakis et al., (2013, 2016 forthcoming), Bhagat et al., (2013), Kang and Ratti (2013, 2015), Gupta et al., (2014), Mensi et al., (2014, 2016), Asgharian et al., (2015), Balcilar et al., (2015a, forthcoming a, b), Brogaard and Detzel (2015), Chang et al., (2015), Chuliá et al., (2015a), Han et al., (2015), Jurado et al., (2015), Ludvigson et al., (2015), Momim and Masih (2015), Redl (2015), Rossi and Sekhposyan (2015), Arouri and Roubaud (2016), Aye et al., (2016a, b), Bekiros et al., (2016, forthcoming), Christou and Gupta (2016), Dakhlaoui and Aloui (2016), Li et al., (2016), Wu et al., (2016),Yang and Jiang (2016), and Arouri et al., (forthcoming)). In general, results seem to suggest that uncertainty negatively impact equity returns, and increases the riskiness (volatility) of the financial markets.

Uncertainty is inherently a latent variable. Hence, obtaining an appropriate measure for it is not straight-forward. While quantifying the impact of uncertainty on financial markets, the above studies have primarily relied on two measures, which are: (i) The News-based approach of Baker et al., (2015) and Brogaard and Detzel (2015), whereby the authors perform month-by-month searches of newspapers for terms related to economic and policy uncertainty to construct their measure of economic and policy uncertainty; (ii) Alternatively, Mumtaz and Zanetti (2013), Mumtaz and Surico (2013), Alessandri and Mumtaz (2014), Mumtaz and Theodoridis (2014, 2015), Carriero et al., (2015) Jurado et al., (2015), Ludvigson et al., (2015), Rossi and Sekhposyan (2015), Rossi et al., (2016), and Shin and Zhong (2016), recover measures of uncertainty from stochastic volatility in the error structure of estimated structural VAR models. ${ }^{1}$ While there exists no clear-cut consensus in terms of which approach to use in constructing measures of uncertainty, the news-based measures of uncertainty, as developed by Baker et al., (2015), seems to have gained tremendous popularity in various applications in macroeconomics and finance. ${ }^{2}$ This is most likely due to the fact that (daily and monthly) data (not only for the US, but also other European and emerging economies) on various types of uncertainties (macroeconomic and financial), based on this approach is easily and freely available for use, and does not require any complicated estimation of a model to generate it in the first place.

In the papers cited above, most of these studies have related the own-country uncertainty with own-country stock returns and/or volatility. There are, however some exception, namely: Sum (2012a, b), Mensi et al., (2014, 2016), Balcilar et al., (2015a, forthcoming a, b), Han et al., (2015), Momim and Masih (2015), and Dakhlaoui and Aloui (2016). ${ }^{3}$ These studies rely on either conditional mean-based vector autoregressive (VAR) models or cross-correlation functions, and quantile regression and quantile causality approaches to relate primarily news-based US uncertainty with emerging stock markets (primarily Brazil, China, India, Russia and South Africa (BRICS) and at times some east-Asian economies). While VARs and quantile regressions (modelling contemporaneous US uncertainty) often show insignificant effects (Sum (2012a, b),

\footnotetext{
1 Though not as technical as the structural VAR based approaches, Bali et al., (2015) recovers a measure of uncertainty based on a weighted average of the dispersion of many macroeconomic variables.

2 See Strobel (2015) for a detailed review of alternative measures of uncertainty.

3 Studies like Balcilar et al., (2016) and Cheng et al., (2016) tend to analyze the impact of somewhat exogenous measures of uncertainty (see Ludvigson et al., (2015) on a discussion of endogeneity of uncertainty), like geopolitical risks and partisan conflict rather than policy or equity market uncertainty, on BRICS, and US and Euro Area stock markets respectively.
} 
Mensi et al., (2014, 2016), Han et al., (2015), Momim and Masih (2015)), quantile causality tends to provide consistent evidence of strong spillovers from US uncertainty onto financial markets of developing countries (see for example, Balcilar et al., (2015a, forthcoming a)). ${ }^{4}$ While, the quantile causality used in Balcilar et al., (2015a, forthcoming a) are of value; one major drawback of this approach is that it does not provide any information regarding the sign and persistence of the impact of US uncertainty - both valuable source of information for international investors. These aspects are important in the areas of risk management, portfolio allocation, asset pricing, and option pricing. Note that, an increase in US uncertainty can either negatively or positively affect international stock markets. Given the dominance of the US in the global economy, a more uncertain environment in the US economy leading to a contraction in the US stock market (as shown in the literature cited above) can lead to a decline in stock returns of other markets through spillovers either via the stock markets (Chuliá et al., 2015a; Balcilar et al., 2015b) or through the linkage between US and global uncertainties (Ajmi et al., 2014; Klößner and Sekkel, 2014; Yin and Han, 2014; Gupta et al., 2016). On the other hand, an increase in US uncertainty could lead to an improvement in foreign stock markets through the diversification channel of investor portfolios (Mensi et al., 2014, 2016; Balcilar et al., 2015a, forthcoming a, b).

Against this backdrop of the above mentioned literature, the objective of our paper is to use quantile impulse-response functions obtained from a multivariate quantile models (MVQM), to analyze the impact of US uncertainty on the stock returns of the US itself and, in line with the literature discussed above, on the emerging markets of Brazil, China, India, Russia and South Africa, i.e., (the BRICS countries). ${ }^{5}$ In addition, we also investigate the effects on the mature European markets of France, Germany and the UK, for the sake of comparability of the effect of US uncertainty on emerging and developed markets. To the best of our knowledge, this is the first attempt to use quantile-based impulse response functions to study the impact of US uncertainty in terms of magnitude, sign and persistence on domestic and foreign equity markets. Note that, the decision to rely on a quantile-based approach is due to the favorable evidence provided by the causality-in-quantiles test, as discussed above. In addition to this, there are several other advantages to using the quantile model: First, it is inherently a nonlinear model, as it allows the parameter estimates to vary across the quantiles of the variables involved. In the process, it can capture various phases of the equity markets, depending on the quantiles we are looking at. For instance, lower (higher) quantiles suggest bear (bull) regime, while the median indicates the functioning of the market at its average mode. In other words, one can capture asymmetric effects (if it exists) depending on what part of the conditional distribution of the dependent variable we are looking at. Second, it is quite well-known that stock returns have heavy-tails; naturally then, a quantile model is more appropriate in capturing the skewed distribution by considering the important information content at the extreme ends of the

\footnotetext{
4 At times, incorporating time-variation in estimation also provide intermittent evidence of the effect of foreign uncertainties on domestic economies (see for example, Dakhlaoui and Aloui (2016) and Balcilar et al., (forthcoming b)).

${ }_{5}^{5}$ Note the literature on uncertainty and stock markets generally motivates the choice of the BRICS countries as main emerging markets, on the ground that these economies have grown rapidly and have become more integrated with the developed world in terms of trade and investment. These countries also account for more than one-fourth of the world's land area, more than 40 percent of the world's population and about 15 percent of global GDP (Mensi et al., 2014). Understandably, the current and potential growth of the BRICS countries has important implications for the capitalization of their stock markets, along with their financial dependence with other stock markets. The four BRIC countries are expected to account for $41 \%$ of the world's stock market capitalization by 2030, with China overtaking the United States in equity market capitalization, to become the largest equity market in the world (Mensi et al., 2014). In addition, South Africa has also witnessed rapid financial market development and sophistication, and is also one of the world's largest producer of some strategic commodities (gold, platinum, and chrome), which in turn, are vital resources to support domestic and global economic growth. Given this, South Africa's presence in the BRICS group provides opportunities to establish a dedicated investment strategy in terms of economic diversification opportunities (Cakan and Gupta, 2016).
} 
distribution, which conditional mean-based models would fail to capture. Finally, being a nonlinear approach, it helps us to model the well-known fact that equity markets not only evolve in a nonlinear fashion, but are also related to its determinants in a nonlinear fashion (see Bekiros et al., (forthcoming), Chuliá et al., (2015a), Balcilar et al., (2015a, b; forthcoming a) for detailed discussions in this regard).

We employ daily observations covering the period of January, 1998 to March, 2016 to capture high-frequency effects of US uncertainty. Again, deviating from the literature which has relied on monthly news-based economic policy uncertainty (EPU) measures, we not only analyze the impact of daily US EPU, but also its daily equity market uncertainty (EMU). Note that, since other countries do not have daily measures of EPU and EMU, it is not possible for us to analyze the impact of one's own measure of daily uncertainties on domestic financial markets. Previewing our results, we find that during a bear regime, an uncertainty shock reduces stock market returns; both in mature and emerging markets, but in higher magnitudes for the latter. However, these shocks are found to increase returns at highest quantiles for the mature markets. Policy uncertainty is a less relevant factor, but still it impacts negatively the stock market dynamics during episodes of financial distress, especially for the emerging markets. These results contrast with the market reactions to uncertainty in the median scenarios, which tend to be insignificant in all the cases considered. The remainder of the paper is organized as follows: Section 2 discusses the methodology, while Section 3 outlines the data used, and presents the results. Finally, Section 4 concludes.

\section{Methodology}

Quantile regression allows for the analysis of the linkage between economic variables across the full conditional distribution of the dependent variable. In the traditional quantile regression, the quantiles of a dependent variable are assumed to be linearly dependent on a set of conditioning variables, which are assumed exogenous. However, as in any structural modeling set up, causal relationships can be identified, only after imposing a set of exogeneity conditions on the data generating process. We incorporate our exogeneity restrictions by using a recursive identification scheme (a Cholesky factorization), in the context of a vector autoregresion system, as is traditionally done following Sims (1980). Nevertheless, our reduced-form VAR is fitted to different quantiles of the series, instead of their conditional means. With this approach, we aim at measuring the reaction of the stock markets in our sample, facing an uncertainty shock, at different fragments of the stock returns distributions.

Multivariate multiquantile models (MVMQ), in reduced and structural forms, have been recently introduced in the econometrics field by White et al. (2015) as a multivariate extension of CAViaR models developed by Engle and Maganelli (2004). White et al. (2015), using a bivariate MVMQ $(1,1)$, that is, a model with one lag in both, the exogenous and endogenous variables, addressed different issues related to systemic risk in the global banking sector.

The general idea underlying MVMQ models is that the quantiles of the distribution of a time series $r_{t}$ may depend on its own lags and on the lags of certain covariates of interest, such as equity market uncertainty, or economic policy uncertainty, $\left(u_{t}\right)$. Particularly, the MVMQ $(1,1)$ model used in this study is given by the following two equations:

$$
q_{r t}=c_{r}(\theta)+a_{r r}(\theta)\left|r_{t-1}\right|+a_{r u}(\theta)\left|u_{t-1}\right|+b_{r r}(\theta) q_{r t-1}+b_{r u}(\theta) q_{u t-1},
$$




$$
q_{u t}=c_{u}(\theta)+a_{u r}(\theta)\left|r_{1 t-1}\right|+a_{u u}(\theta)\left|u_{t-1}\right|+b_{u r}(\theta) q_{r t-1}+b_{u u}(\theta) q_{u t-1}
$$

or more compactly by:

$$
q_{t}=c+A\left|R_{t-1}\right|+B q_{t-1}
$$

where $q_{r t}$ is implicitly defined as $\operatorname{Pr}\left[r_{t} \leq q_{r t} \mid \mathcal{F}_{t-1}\right]=\theta$, in the case of stock returns, and, analogously, $\operatorname{Pr}\left[u_{t} \leq q_{u t} \mid \mathcal{F}_{t-1}\right]=\theta$, in the case of the uncertainty series. In other words, quantiles of stock return series $r_{t}$, at level $\theta$, depend on its own lags through the coefficient $b_{r r}$; on lags of the stock returns trough $a_{r r}$; on lags of uncertainty, via $a_{r u}$; and, importantly, on lags of the uncertainty-quantiles, thanks to the coefficient $b_{r u}$. The same holds, conversely, for the process that describes the dynamics of the uncertainty index.

Note from equation 1 and 2, that there are no contemporaneous RHS variables in our model, which if present may be correlated with the error term. In this case, the timing of the news appearances would be an issue, because technically it could be the case that the uncertainty index captures information which has been not released to the market in a different time zone (for example, the Chinese market closes before the news in the US market are produced). For this reason, the coefficients of our bivariate systems are estimated using lagged returns, lagged uncertainty indexes, and lagged quantiles of the series. In this way, we guarantee that the news have been released before the market return is generated. Note also that the elements in the main diagonal of the matrix $B$ quantify the dependence of the quantiles on its own lags. In contrast, elements outside the main diagonal measure the tail codependence between the quantile series of returns and uncertainty, in a direct fashion.

Assuming one suitable exogeneity restriction in the system, it is possible to identify the structural innovations in our system. In this case, quantile pseudo impulse-response functions (PQIRF) proposed by White et al. (2015) would be available for the analysis. In this study we assume that US uncertainty indexes (EPU and EMU) are contemporaneously exogenous to the market returns, while market returns react instantaneously to uncertainty conditions. In other words, the US EPU or EMU is ordered first in the VAR, which in turn, is in line with the studies analyzing the impact of US uncertainty on foreign economies (see for example, Sum (2012a, b), Colombo (2013), Jones and Olson (2015), and Cheng et al., (2016)). This is a realistic assumption on the grounds that, given the dominance of the US economy, its uncertainty leads other financial markets. As far as the ordering in the quantile VAR of the US economy is concerned, for the sake of comparability with the other countries considered in our paper, uncertainty is ordered first again. This is in line with the evidence of US stock market predictability emanating from uncertainty as provided by Bekiros et al., (2016, forthcoming).

PQIRFs differ from traditional functions because, unlike the latter where a one-off intervention $\delta$ is given to the error term, PQIRFs assume that the one-off intervention $\delta$ is given to the observable uncertainty index $u_{t}$ only at time $t$. At all other times there is no change in $u_{t}$. In this way, the pseudo $\theta$ th quantile impulse-response function for the $i$-th market in our sample, $r_{i t}$ is defined as: 


$$
\Delta_{i, s}\left(\tilde{r}_{i t}\right)=\tilde{q}_{i r, t+s}-q_{i r, t+s}, \quad s=1,2,3 \ldots T
$$

where $\tilde{q}_{i r, t+s}$ is the $\theta$ th-conditional quantile of the treated series, $\tilde{r}_{i t}$, and $q_{r i, t+s}$ is $\theta$ thconditional quantile of the contra-factual series, $r_{i t}$. One advantage of PQIRFs is that they retain the traditional interpretation of IRFs, even when they can be calculated for different quantiles of the distribution. In this way, they allow us to enhance the analysis of extreme codependences between pairs of time series, approaching the problem of estimating tail dependences directly, in the case of sufficiently high or low quantiles.

\section{Data and Results}

\subsection{Data}

We use the EMU and EPU indices, developed by Baker et al., (2015), as two measures of the degree of uncertainty in the US economy. Data on these two measures of uncertainty come from the website: http://www.policyuncertainty.com. The daily news-based EPU index uses newspaper archives from Access World New's NewsBank service. The primary measure for this index equals the number of articles that contain at least one term from each of 3 sets of terms, namely, economic or economy, uncertain or uncertainty, and legislation, deficit, regulation, Congress, Federal Reserve, or White House. ${ }^{6}$ Using the same news source, the EMU index searches for articles containing the terms uncertainty or uncertain, economic or economy, and one or more of the following terms: equity market, equity price, stock market, or stock price. ${ }^{7}$ We use the natural logarithms of EPU and EMU, since both these variables are found to be stationary at log-levels based on standard tests of unit roots. ${ }^{8}$

We use the daily stock price of the emerging BRICS countries, and that of the four mature markets of France, Germany, UK and US. These data come from Thomson Reuters' Datastream database. We express stock prices as compounded daily returns (i.e., the natural logarithmic difference expressed in percentage). Note that, instead of using the VIX, ${ }^{9}$ a popular measure of the implied volatility of S\&P 500 index options, we use the news-based measure of EMU index to ensure that both our measures of uncertainty are derived in a similar method (i.e., news articles-based and, hence, the results, in terms of their relationship with stock prices, are comparable). ${ }^{10}$ Our data covers the sample period of $28^{\text {th }}$ January, 1998 through $17^{\text {th }}$ March, 2016, with the start and end dates being purely driven by data availability (at the time of writing this paper) on the three variables of interest for all countries involved. Table A1 in the Appendix of the paper provides the basic summary statistics of the nine stock returns and the EPU and EMU indexes. As can be seen from the Jarque-Bera (J-B) test, the null of normality is strongly rejected for both the stock returns and the uncertainty indices at the highest level of significance, which in turn, provides a strong motivation to rely on a quantile-based VAR.

\subsection{Results}

\footnotetext{
${ }^{6}$ Further details appear at: http://www.policyuncertainty.com/us daily.html.

${ }^{7}$ Additional details are available at: http://www.policyuncertainty.com/equity uncert.html.

${ }^{8}$ Complete details of the unit root tests are available upon request from the authors.

9 Often referred to as the fear index or the fear gauge, it represents one measure of the market's expectation of stock-market volatility over the next 30 day period.

${ }^{10}$ As indicated at: http://www.policyuncertainty.com/equity uncert.html, the EMU exhibits a contemporaneous daily correlation with the VIX of over 0.3 .
} 
In Figure 1, we present the stock market returns and the estimated quantiles using the model explained in equation 3 , where the uncertainty index, $u_{t}$ corresponds to EMU, and $r_{t}$ is the series of stock returns, for each market. As can be noticed, the quantiles do cover the expected variation of the markets. One would expect that observations above the $99^{\text {th }}$ percentile or below the $1^{\text {st }}$ percentile represent about $1 \%$ of the total sample.

For the last reason, we calculated the percentage of observations within the sample that exceed the $99^{\text {th }}$ and $1^{\text {st }}$ percentiles in absolute value. For the MVMQ model, where $\theta=0.01$, the percentage of stock returns that were lower than the estimated percentile, lay between $0.99 \%$ (US, UK, France, China, Brazil) and 1.01\% (Germany, India, Russia and South Africa). On the right tail, when $\theta=0.99$, the percentage of the stock returns in the sample that exceeded the $99^{\text {th }}$ percentile, were $0.99 \%$ for US, UK and Brazil, $0.97 \%$ for France, $1.03 \%$ for Germany and China and $1.01 \%$ for India, Russia and South Africa.

In the case of the model that used the EPU index, we found a similar adjustment to the data, with a percentage of exceedances between $0.99 \%$ and $1.01 \%$, at both tails of the distributions. We do not report the results or the figures here, but they are available for the interested reader.

In all the cases, the MVMQ quantiles capture the dynamics of the market in an accurate fashion, and they are sensitive enough to situations of market distress or booms, as the ones observed in the periods around years 2001-2003 and 2008-2009; or the beginning of our sample period, in the case of Russia.

Figure 1. Stock market returns and quantiles estimated using the EMU index.

\section{USA}

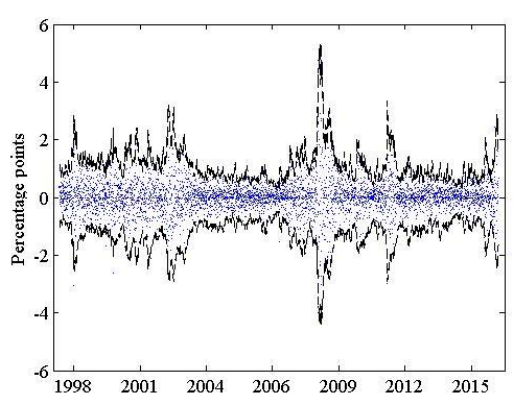

UK

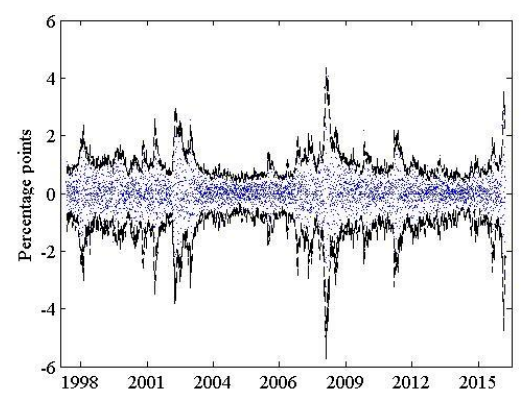

China
Germany

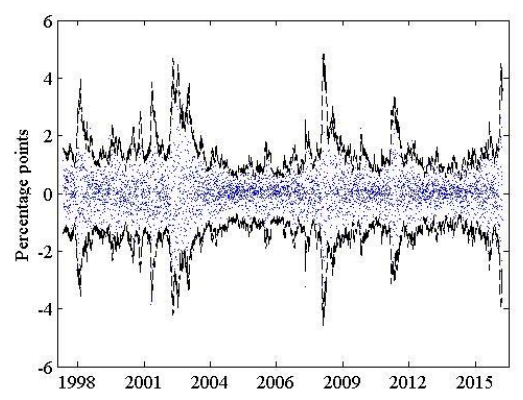

Brazil

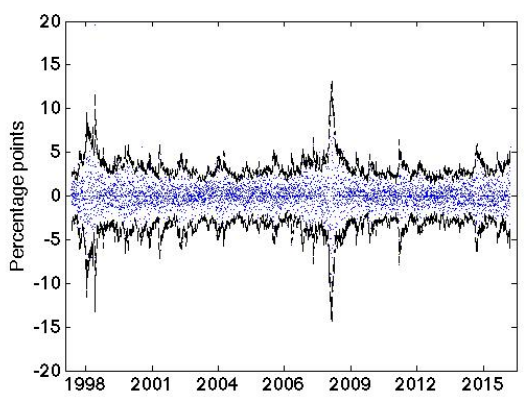

India
France

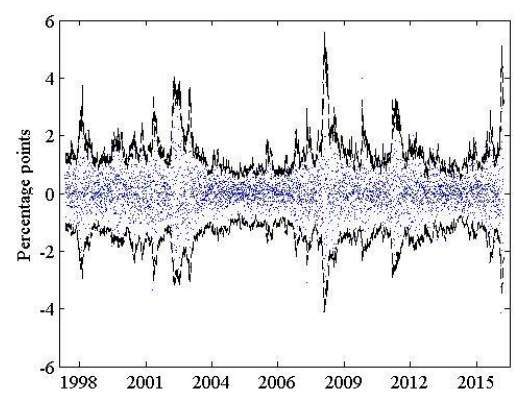

Russia

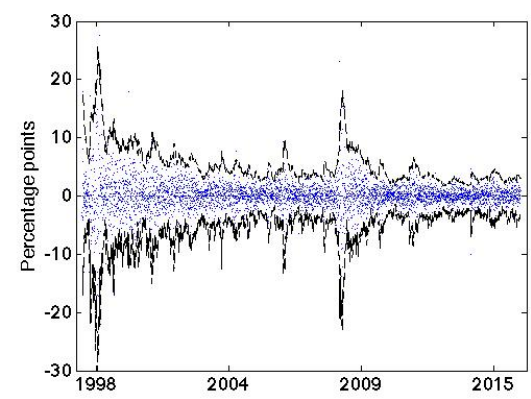

South Africa 

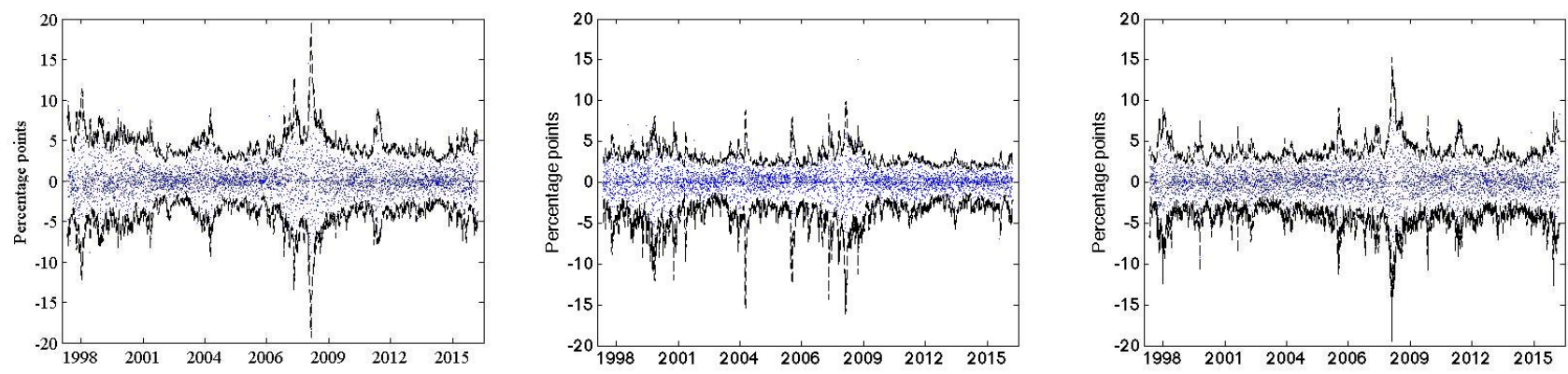

Note: The figure shows the daily stock market returns joint with the conditional quantiles estimated using the MVMQ $(1,1)$ model, between each market and the EMU index, as explained in the main text. Black dotted lines are the $1^{\text {st }}$ and $99^{\text {th }}$ percentiles, while the blue dots are the daily stock market returns.

Modeling directly the quantiles of the market returns allows us to document whether the volatility responses of these markets, following and uncertainty shock, are symmetric or not. In the cases where the response is symmetric, a structural GARCH model augmented with exogenous variables, including uncertainty, would be enough to capture the main features of the volatility series. Otherwise, traditional GARCH or stochastic volatility models would be unable to capture the asymmetric nature of the market volatility, conditioned on an uncertainty shock. In the latter case, less parsimonious modeling strategies such as including indicator variables in the variance equation could be explored, but the MVMQ modeling strategy is simpler and intuitive, and would require less restrictive assumptions. ${ }^{11}$

\subsubsection{Stock Market's Reactions to Equity Market Uncertainty (EMU)}

In Table 1 we summarize the results of the reduced-form VAR-quantile by means of the joint cross-dependence statistic between each market and the market uncertainty series. This statistic tests whether the series of stock returns and the EMU indexes show evidence of co-dependence at different quantiles of their bivariate distribution.

The results are enlightening about the sort of dependency arising between market uncertainty and stock markets. In most of the cases the null of non-dependency is rejected. This means that, indeed, uncertainty impacts the dynamics of the stock returns in a significant fashion. For example, in the case of France, the cross-dependence statistic (js) is equal to 29.12 at the $1^{\text {st }}$ percentile; which means that the joint hypothesis under which $a_{r u}(\theta=0.01)=a_{b u}(\theta=$ $0.01)=0$ is rejected at $99 \%$ of confidence.

In general lines, on the one hand, regarding the mature markets in our sample, we found that only for Germany there is not cross-dependency with market uncertainty at the $1^{\text {st }}$ percentile, in the reduced-form model. While at the median, and the $99^{\text {th }}$ percentile, the null is rejected for all the markets.

\footnotetext{
${ }^{11}$ Based on the suggestions of an anonymous referee, we also estimated GARCH models to analyse the impact of EMU and EPU on stock returns and volatility, but could not detect any significant effects. These results clearly highlight the superiority of using our quantile-based approach over the conditiona-mean-based estimation of the GARCH models, which in turn, fails to capture the role of heavy-tails in the data. Complete details of the estimation of the GARCH models are available upon request from the authors.
} 
On the other hand, for the BRICS, although uncertainty is statistically significant in most of the cases alike, there are important exceptions. At $99^{\text {th }}$ percentile there is not tail-dependency between market uncertainty in the US market and stock returns in Russia, India, South Africa and China (at 99\% of confidence). Nor there is tail dependence, in the reduced-form model, between the stock market returns in the Brazilian market and market uncertainty in the US, at the $1^{\text {st }}$ and $50^{\text {th }}$ percentiles of their bivariate distribution. 
Table 1. Cross-dependence between stock returns and equity market uncertainty at different quantiles.

\section{Mature Markets}

\begin{tabular}{lccccccccc}
\hline & \multicolumn{2}{c}{ United States } & \multicolumn{2}{c}{ Germany } & \multicolumn{2}{c}{ France } & \multicolumn{2}{c}{ United Kingdom } \\
\hline & statistic & p-value & statistic & p-value & statistic & p-value & statistic & p-value \\
\cline { 2 - 10 } 1st Percentile & 23.03 & $<0.001$ & 8.47 & 0.08 & 29.12 & $<0.001$ & 22.41 & $<0.001$ \\
50th Percentile & 312.41 & $<0.001$ & 308.80 & $<0.001$ & 237.22 & $<0.001$ & 274.50 & $<0.001$ \\
99th Percentile & 17.74 & $<0.001$ & 16.94 & $<0.001$ & 32.58 & $<0.001$ & 30.59 & $<0.001$ \\
\hline
\end{tabular}

\section{BRICS}

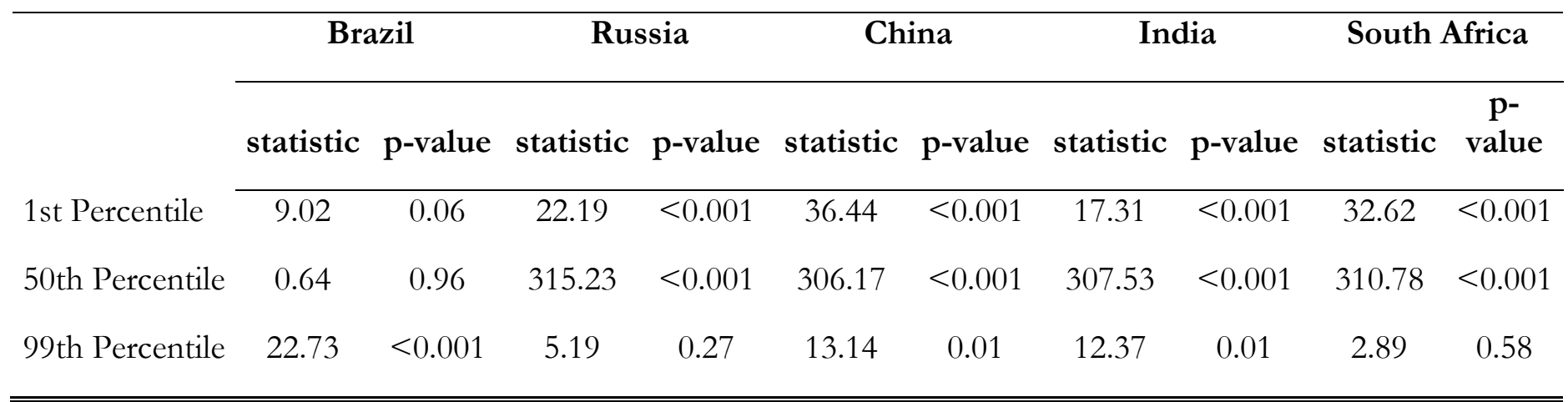

Note: the statistic reported for each market, tests whether the quantiles of the stock returns depend on the first lag of uncertainty and the first lag of the uncertainty's quantiles. That it, it tests the joint cross-dependency among the series, under the null of independency. The results are estimated at three different quantiles, the 1st, 50th, and 99th percentiles. 
Up to here, market uncertainty seems a relevant variable affecting stock markets dynamics around the world, both at the center of the distributions and at the tails. Nevertheless, these preliminary analyses must be approached with caution because they do not take into account the structural innovations in the system, which in turn, depend on the full set of coefficients contained in matrixes $A$ and $B$, in equation 3 , and on the structural identification assumptions. For this reason, we reported the PQIRFs of the stock markets, following and uncertainty shock. That is, Figure 2 and 3 plot the reaction of each stock market, in a horizon of 15 days, after an uncertainty shock has occurred in the US market.

Figure 2 reads as follows. After a positive shock to the equity market uncertainty, the $1^{\text {st }}$ percentile of the four mature market returns in our sample, US, Germany, France and UK decrease. That is, at the lowest quantiles, which naturally match bearish-riskier markets, an uncertainty shock worsens the situation, conducing to even lower returns. Alternatively, this can be understood as an increment in the Value-at-Risk statistic, in a horizon of one day, at $99 \%$ of confidence, due to an increase in uncertainty. The effects of the uncertainty shock at the lowest quantile last approximately between five and seven days. After that, they disappear.

When we focus on the higher quantiles of the stock returns distributions, for example, the $99^{\text {th }}$ percentile, we found that the uncertainty shock has smaller effects. In the case of Germany the effect is indeed non-significantly different from zero. In the cases of UK, and US although significant, the effect is considerably lower than the impact documented at the $1^{\text {st }}$ percentile. Only for France the shocks at the two tails of the distribution seem remarkably similar. Nevertheless, when they are significant, the effects at the $99^{\text {th }}$ percentile are positive. This means than, during bullish episodes, the effects are small, but they tend to increase the market rally. This situation could obey to the fact that, at the highest percentiles, an increment in uncertainty may induce a reallocation of capital in favor of the most developed markets, increasing the returns at the right tail of their distributions, to the detriment of less developed markets. Finally, in contrast, for the median scenario, the effects tend to be non-significant in all the markets.

The observations above suggest us that uncertainty is an important consideration at extreme market scenarios such as pronounced rallies or market distress, but even more for the latter. During regular times, uncertainty is not a first order market consideration. 
Figure 2. Equity Market Uncertainty Spillovers to Stock Markets Returns:

\section{Mature Markets}

\section{United States}

1st Percentile
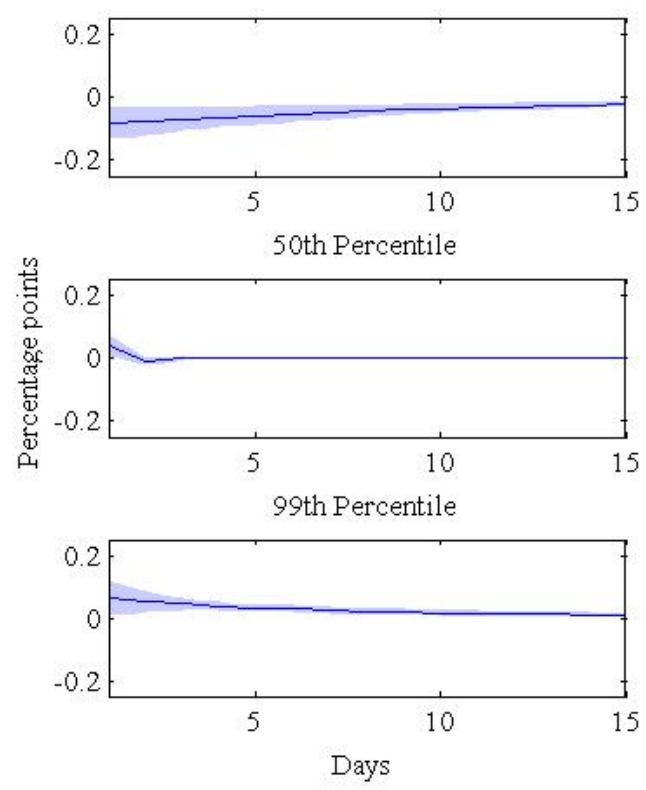

France
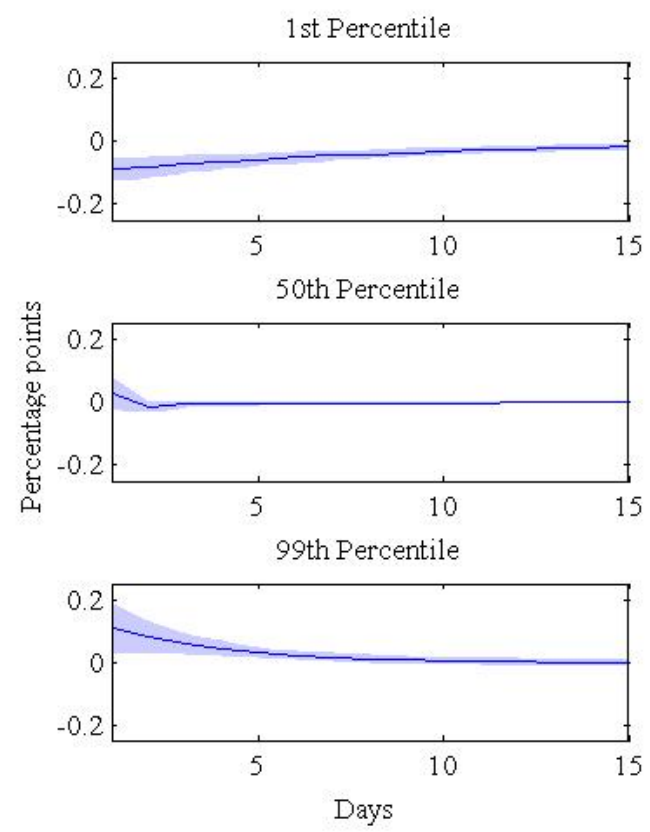

Germany
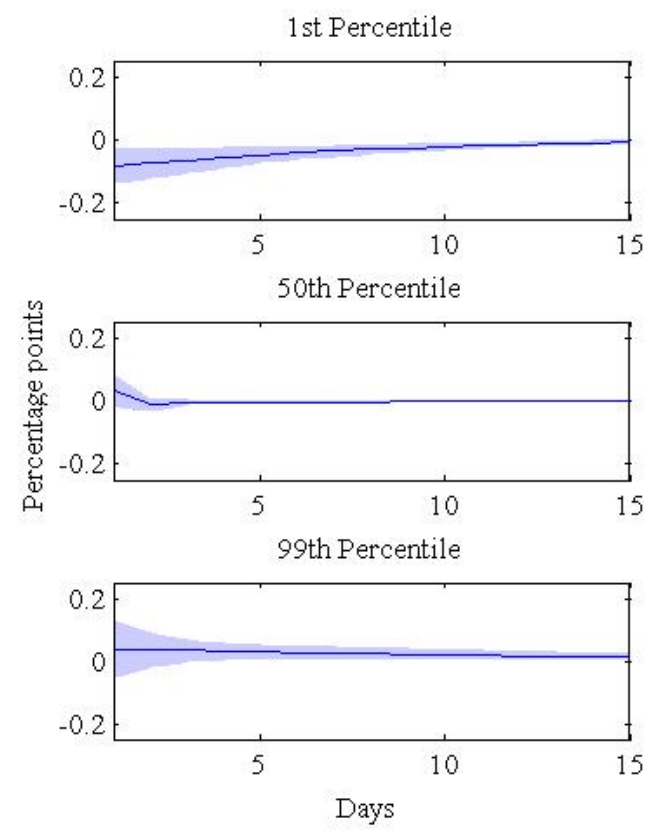

United Kingdom
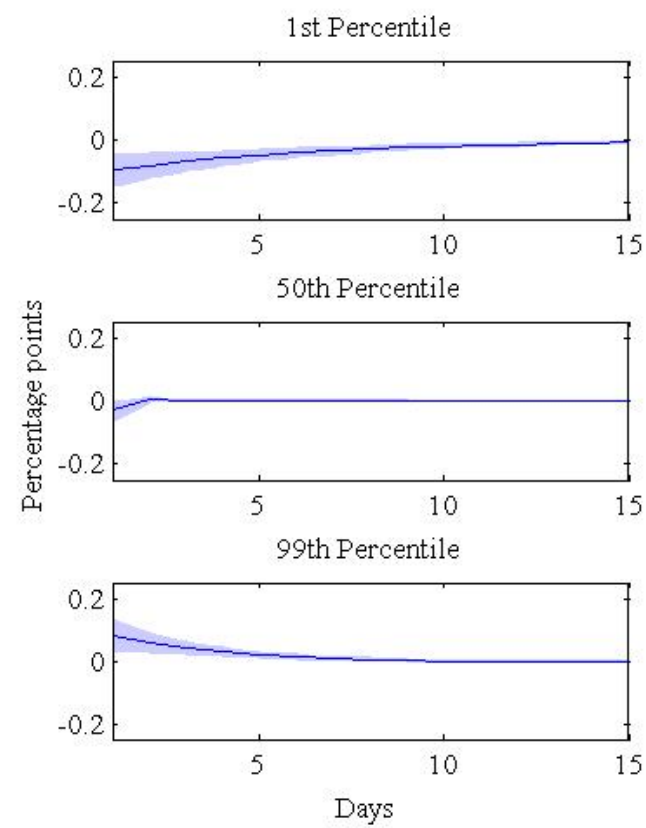

Note: The figure shows the pseudo quantile impulse response functions of the four mature markets in our sample, following an equity market uncertainty shock in the US. The shock is equal to a one-standard deviation of the uncertainty index. The shadowed area is the 95\% asymptotic confidence interval provided by White et al. (2015). Each system is bivariate and it includes the EMU index in logs and the stock returns of each market, in percentage points. 
Regarding the emerging markets in our sample, Figure 3 shows us a heterogeneous panorama. That is, uncertainty tends to be a relevant factor only during market distress scenarios, i.e. lowest quantiles. With the exception of Brazil, the uncertainty shock produces non-significant effects on the market returns during bullish scenarios (the PQIRFs at $99^{\text {th }}$ percentile cover zero, in the cases of Russia, India, South Africa and China). Brazil houses symmetric effects at both tails of its distribution, meaning that an uncertainty shock increases its $99^{\text {th }}$ percentile and decreases its $1^{\text {st }}$ percentile. Only in the case of Russia, the uncertainty shock in the US does not produce significant effects at the $1^{\text {st }}$ percentile, neither. Regarding the median scenarios, for three markets the effects are statistically significant and negative. Namely, Russia, China and South Africa, but in all the cases those effects last only one day.

Notice as well that the effects at the lowest quantiles, are also bigger in magnitude than those for the developed markets, showing us that BRICS, excluding Russia, are more sensitive to uncertainty shocks in the US' market, than the developed markets, under scenarios of financial distress. 
Figure 3. Equity Market Uncertainty Spillovers to Stock Markets Returns:

\section{BRICS' Markets}

Brazil
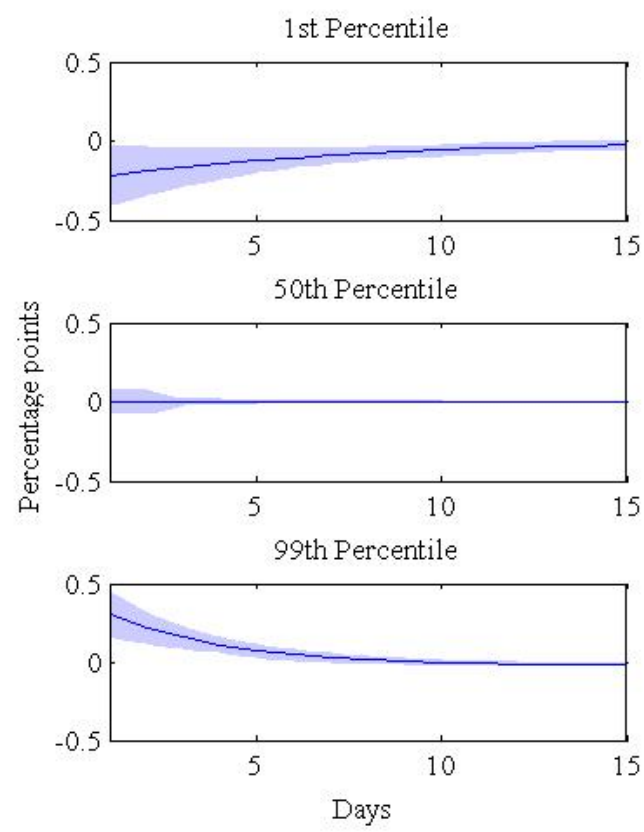

India
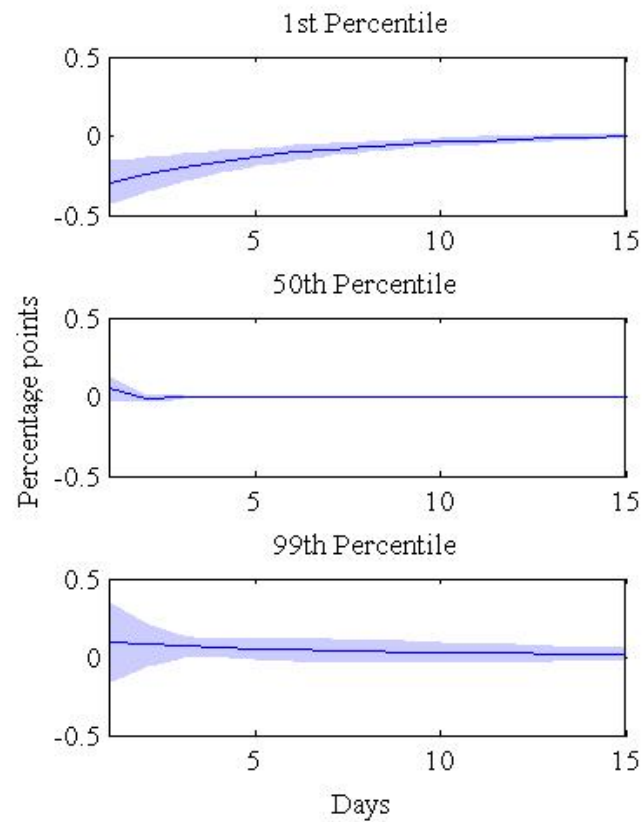

Russia
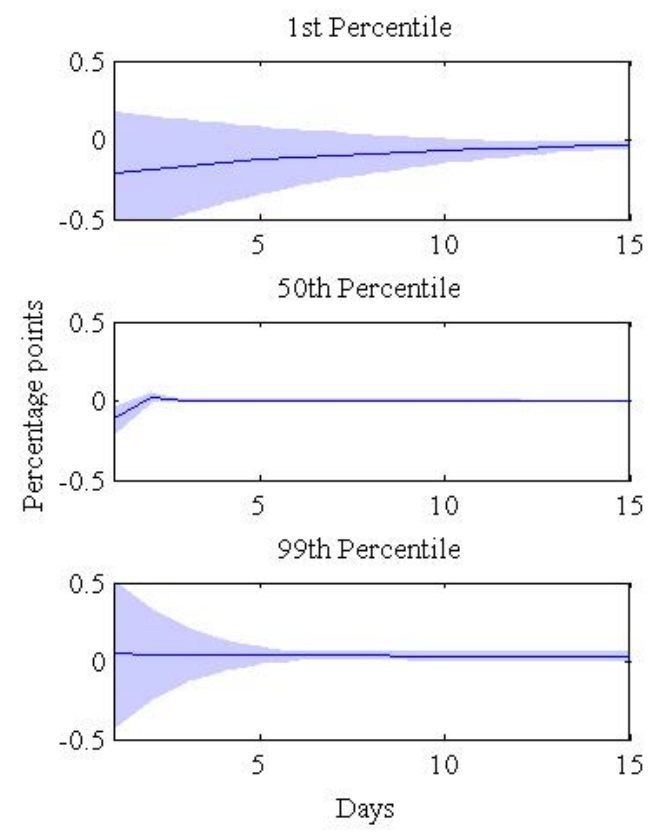

China
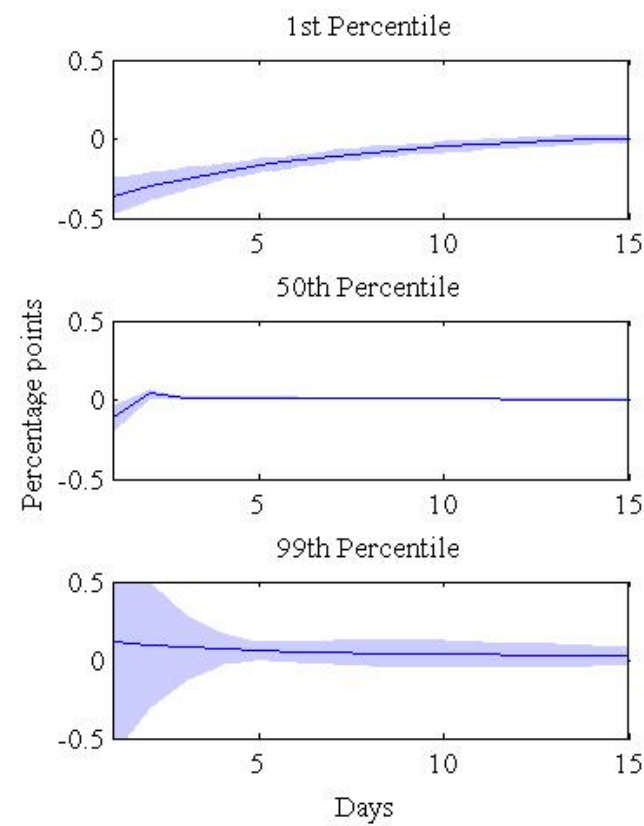


\section{South Africa}
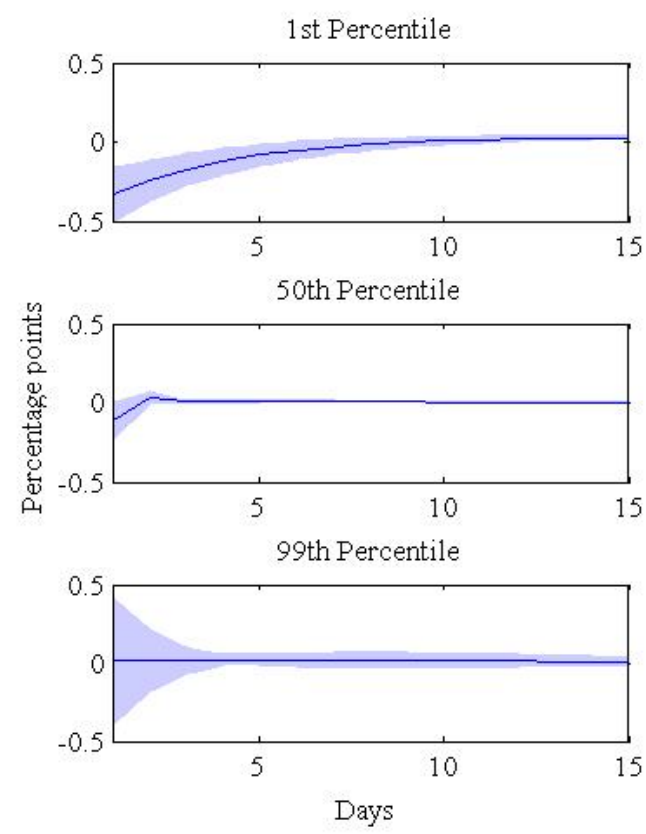

Note: The figure shows the pseudo quantile impulse response functions of the BRICS markets, following an equity market uncertainty shock in the US. The shock is equal to a one-standard deviation of the uncertainty index. The shadowed area is the $95 \%$ asymptotic confidence interval provided by White et al. (2015). Each system is bivariate and it includes the EMU index in logs and the stock returns of each market, in percentage points. 
Based on the suggestions of an anonymous referee, we have moved the results and the discussion associated with the EPU to the Appendix of the paper. This we believe makes sense, given that, while EMU is an uncertainty related directly with the equity market of the US, EPU is a form of uncertainty primarily associated with economic policies. But, given that these two indices are distinct based on certain set of search terms comprising them (see Data segment), we did not want to completely remove the EPU results from the paper, and hence, created an extensive Appendix. Also note, the decision to keep the EPU results is to make our analysis comparable with the literature discussed above, which in turn, has primarily used the EPU index, but at lower frequencies. In any event, when we compare our results between EMU and EMPU, overall, EPU seems a less relevant consideration for stock markets around the world compared to EMU, and this most likely due to the fact that the terms comprising the EMU index involves stock markets. It matters the most at the lowest percentiles, when bearish markets are recorded and, when significant, those impacts on the BRICS markets are higher than on the mature markets of our sample. The persistence of the EPU shocks is also lower, between 4 and 5 days, than the persistence of an EMU shock. ${ }^{12}$

\section{Concluding Remarks}

In the wake of the recent global financial crisis, large amount of research has been devoted to measuring uncertainty - an inherently unobservable variable, and its impact on international financial markets. However, the literature has primarily analyzed the impact of domestic uncertainty on its own stock markets based on conditional-mean based models, and ignored the importance of the US uncertainty, even when literature has provided evidence of uncertainty spillovers from the US. However, given that stock markets have heavy-tails, conditional meanbased models are likely to leave out important information and lead to inaccurate conclusions. While some exceptions exist in terms of using causality-in-quantiles approach to analyze the impact of domestic and global uncertainties on domestic stock markets, these approaches are silent about the sign, magnitude and persistence of such effects - all of which are important information for international investors. Given this, our paper is the first in the literature to use quantile impulse-response functions obtained from multivariate quantile models (MVQM), to analyze the impact of US policy and equity market on the stock returns of the BRICS and four mature markets, namely, France, Germany, UK and US.

Based on daily data covering the period of January 1998 to March 2016, we find some important results. Regarding the effects of equity market uncertainty on mature markets, we find that during episodes of financial distress, an uncertainty shock reduces the 1 st percentile, while it increases the 99th percentile during market booms. That is, uncertainty shocks produce momentum in mature markets, during extreme market scenarios, either positive or negative. Reactions in the BRICS markets are stronger compared to the mature markets at the left tail of the distribution, and no significant at the right tail (excepting Brazil). This means that, for emerging markets, uncertainty worsens the situation during negative market scenarios, but is has no effect when the market setting is positive.

\footnotetext{
${ }^{12}$ Based on the suggestions of an anonymous referee, we also estimated standard quantile regressions to analyze the contemporaneous impact of EMU and EPU. As with our QVAR model results, we observed that contemporaneous EMU and EMU again tends to have stronger impact at the tails of the conditional distribution of absolute returns. Complete details of these results are available upon request from the authors.
} 
As regards to economic policy uncertainty, it seems a less relevant consideration for stock markets compared to EMU. In general, uncertainty tends to produce non-significant responses in mature markets. For the emerging markets, policy uncertainty shocks produce significant effects, especially during market distress scenarios, with Brazil, India and South Africa experience a negative reaction.

Finally, for both equity market and economic policy uncertainty, the median responses of the markets, tend to be statistically insignificant in most of the cases, and they lack persistence when they are different from zero.

Our results have important implications for international investors in the sense that these results highlight the importance of modeling the asymmetric effects of uncertainty, which in turn, would provide relevant information in the areas of risk management, portfolio allocation, asset pricing, and option pricing. While our analysis provides in-sample evidence of the effect of economic policy and equity market uncertainties on mature and emerging markets, as part of future research, it would be interesting to check if our results hold in an out-of-sample forecasting exercise. In the process, we will be able to add to the huge literature on international stock market predictability (see Rapach and Zhou (2013) and Aye et al., (forthcoming) for detailed literature reviews), but based on high frequency data on uncertainty from a quantile model perspective, which would allow us to forecast various phases of financial markets. In addition, while in this paper we use daily measures of uncertainty for the US economy only (which in turn is undoubtedly the most important global economy), as part of future research, it will be worthwhile to develop such indices for other developed and emerging markets as well. This will allow us to compare the importance of domestic uncertainty shocks relative to the foreign ones.

\section{Acknowledgements}

Helena Chuliá and Jorge M. Uribe gratefully acknowledge financial support from the Spanish Ministry of Economy [grant numbers ECO2015-66314-R, ECO2016-76203-C2-2-P]. 


\section{References}

Ajmi, A. N., Gupta, R., \& Kanda, P. (2014). Causality between economic policy uncertainty across countries: Evidence from linear and nonlinear tests. Frontiers in Finance and Economics, 11(1), 73-102.

Alessandri, P., \& Mumtaz, H. (2014). Financial regimes and uncertainty shocks. School of Economics and Finance, Queen Mary University of London, Working Paper No. 729.

Antonakakis, N., Chatziantoniou, I., \& Filis, G. (2013). Dynamic co-movements between stock market returns and policy uncertainty. Economics Letters, 120(1), 87-92.

Antonakakis, N. Babalos, V., \& Kyei, C. (Forthcoming). Predictability of Sustainable Investments and the Role of Uncertainty: Evidence from a Non-Parametric Causality-inQuantiles Test. Applied Economics.

Antonakakis, N. Balcilar, M., Gupta, R., \& Kyei, C. (2016). Components of Economic Policy Uncertainty and Predictability of US Stock Returns and Volatility: Evidence from a Nonparametric Causality-in-Quantile Approach, Department of Economics, University of Pretoria, Working Paper No. 201639.

Arouri, M., Estay, C., Rault, C., \& Roubaud, D. (Forthcoming) Economic policy uncertainty and stock markets: Long-run evidence from the US. Finance Research Letters,

Arouri, M., \& Roubaud, D. (2016). On the determinants of stock market dynamics in emerging countries: the role of economic policy uncertainty in China and India, Economics Bulletin, 36(2), 760-770.

Asgharian, H., Christiansen, C., and \& Hou, A-J, (2015). Effects of macroeconomic uncertainty on the stock and bond markets, Finance Research Letters, 13(C), 10-16.

Aye, G., Deale, F., \& Gupta, R. (2016a). Does Debt Ceiling and Government Shutdown Help in Forecasting the US Equity Risk Premium? Panoeconomicus, 63(2), 273-291.

Aye, G., Balcilar, M., El Montasser, G., Gupta, R., \& Manjezi, N. (2016b). Can Debt Ceiling and Government Shutdown Predict US Real Stock Returns? A Boot-strap Rolling-Window Approach. Economia Internazionale, 69(1), 11-31.

Aye, G. C., Balcilar, M., \& Gupta, R. (Forthcoming). International stock return predictability: Is the role of US time-varying? Empirica.

Baker, S. R., Bloom, N., \& Davis, S. J. (2015). Measuring economic policy uncertainty. National Bureau of Economic Research Working Paper No. w21633.

Balcilar, M., Gupta, R., Kim, W-J., \& Kyei, C. (2015a). The Role of Domestic and Global Economic Policy Uncertainties in Predicting Stock Returns and their Volatility for Hong Kong, Malaysia and South Korea: Evidence from a Nonparametric Causality-in-Quantiles Approach. Department of Economics, University of Pretoria, Working Paper No. 201586. 
Balcilar, M., Gupta, R., Nguyen, D.K., \& Wohar, M.E. (2015b). Causal Effects of the United States and Japan on Pacific-Rim Stock Markets: Nonparametric Quantile Causality Approach. Department of Economics, University of Pretoria, Working Paper No. 201595.

Balcilar, M., Gupta, R., and Kyei, C. (Forthcoming a). South African Stock Returns Predictability using Domestic and Global Economic Policy Uncertainty: Evidence from a Nonparametric Causality-in-Quantiles Approach. Frontiers in Finance and Economics.

Balcilar, M., Gupta, R., Modise, M., \& Muteba Mwamba, J. (Forthcoming b). Predicting South African Equity Premium using Domestic and Global Economic Policy Uncertainty Indices: Evidence from a Bayesian Graphical Model. Frontiers in Finance and Economics.

Balcilar, M., Bonato, M., Demirer, R., \& Gupta, R. (2016). Geopolitical Risks and Stock Market Dynamics of the BRICS, Department of Economics, University of Pretoria, Working Paper No. 201648.

Bali, T. G., Brown, S.J., and Tang, Y. (2015). Macroeconomic Uncertainty and Expected Stock Returns. Georgetown McDonough School of Business Research Paper No. 2407279.

Bekiros, S., Gupta, R., \& Kyei, C. (2016). On economic uncertainty, stock market predictability and nonlinear spillover effects. North American Journal of Economics and Finance, 36, 184191.

Bekiros, S., Gupta, R., \& Majumdar, A. (Forthcoming). Incorporating Economic Policy Uncertainty in US Equity Premium Models: A Nonlinear Predictability Analysis. Finance Research Letters.

Bernanke, B. S. (1983). Irreversibility, Uncertainty, and Cyclical Investment. The Quarterly Journal of Economics, 98(1), 85-106.

Bhagat, S., Ghosh, P., \& Rangan, S. (2013). Economic Policy Uncertainty and Economic Growth in India. Indian Institute of Management, Bangalore, Working Paper No. 407.

Bloom, N. (2009). The impact of uncertainty shocks. Econometrica, 77(3), 623-685. Brogaard, J., Brogaard, J., \& Detzel, A. (2015). The asset-pricing implications of government economic policy uncertainty. Management Science, 61(1), 3-18.

Brogaard, J., Brogaard, J., \& Detzel, A. (2015). The asset-pricing implications of government economic policy uncertainty. Management Science, 61(1), 3-18.

Cakan, E., \& Gupta, R. (2016). Does U.S. Macroeconomic News Make the South African Stock Market Riskier? Department of Economics, University of Pretoria, Working Paper No. 201646.

Carriero, A., Mumtaz, H., Theodoridis, K., \& Theophilopoulou, A. (2015). The Impact of Uncertainty Shocks under Measurement Error: A Proxy SVAR Approach. Journal of Money, Credit and Banking, 47(6), 1223-1238.

Cheng, C-H (Jack)., Hankins, W. A., Chiu, C-W (Jeremy). (2016). Does US partisan conflict matter for the Euro area? Economics Letters, 138, 64-67. 
Chang, T., Chen, W. Y., Gupta, R.., \& Nguyen. D. K. (2015). Are Stock Prices Related to Political Uncertainty Index in OECD Countries? Evidence from Bootstrap Panel Causality Test. Economic Systems, 39(2), 288-300.

Christou, C., and Gupta, R. (2016). Forecasting Equity Premium in a Panel of OECD Countries: The Role of Economic Policy Uncertainty. Department of Economics, University of Pretoria, Working Paper No. 201622.

Chuliá, H., Guillén, M., \& Uribe, J. M. (2015a). Measuring Uncertainty in the Stock Market. IREA-Working Paper No. 201524.

Chuliá, H., Guillén, M., \& Uribe, J. M. (2015b). Spillovers from the United States to Latin America and G7 Stock Markets: A VAR Quantile Analysis. IREA-Working Paper No. 201525.

Colombo, V. (2013). Economic policy uncertainty in the US: Does it matter for the Euro area? Economics Letters, 121(1), 39-42.

Dakhlaoui, I., and Aloui, R. (2016). The interactive relationship between the US economic policy uncertainty and BRIC stock markets, International Economics, 146, 141-157.

Dixit, A. K., \& Pindyck, R. S. (1994). Investment under uncertainty. Princeton University Press.

Engle, R.F, \& Manganelli, S. 2004. CAViaR: Conditional autoregressive Value at Risk by regression quantiles. Journal of Business and Economic Statistics, 22, 367-381.

Gupta, R., Hammoudeh, S., Modise, M. P., \& Nguyen, D. K. (2014). Can economic uncertainty, financial stress and consumer sentiments predict US equity premium? Journal of International Financial Markets, Institutions and Money, 33, 367-378.

Gupta, R., Pierdzioch, C.; Risse, M. (2016). On International Uncertainty Links: BART-Based Empirical Evidence for Canada, Economics Letters, 143, 24-27.

Han, H., Kutan, A. M., \& Ryu, D. (2015). Modeling and predicting the market volatility index: The case of VKOSPI. Economics: The Open-Access, Open-Assessment E-Journal, 9 (2015-35): $1-34$.

Jones, P. M., and Olson, E. (2015). The International Effects of US Uncertainty. International Journal of Finance \& Economics, 20(3), 242-252.

Jurado, K., Ludvigson, S. C., \& Ng, S. (2015). Measuring Uncertainty. The American Economic Review, 105(3), 1177-1216.

Kang, W., \& Ratti, R. A. (2013). Oil shocks, policy uncertainty and stock market return. Journal of International Financial Markets, Institutions and Money, 26, 305-318.

Kang, W., \& Ratti, R. A. (2015). Oil shocks, policy uncertainty and stock returns in China. Economics of Transition, 23(4), 657-676.

Klößner, S. \& R. Sekkel (2014). International spillovers of policy uncertainty. Economics Letters 124: $508-512$. 
Li. X-L., Balcilar. M., Gupta. R., \& Chang. T. (2016). The Causal Relationship between Economic Policy Uncertainty and Stock Returns in China and India: Evidence from a Bootstrap Rolling-Window Approach. Emerging Markets Finance and Trade, 52(3), 674-689.

Ludvigson, S. C., Ma, S., \& Ng, S. (2015). Uncertainty and Business Cycles: Exogenous Impulse or Endogenous Response? National Bureau of Economic Research, Working Paper No. w21803.

Mensi, W., Hammoudeh, S., Reboredo, J. C., \& Nguyen, D. K. (2014). Do global factors impact BRICS stock markets? A quantile regression approach. Emerging Markets Review, 19, 1-17.

Mensi, W., Hammoudeh, S., Yoon, S-M, \& Nguyen, D. K. (2016). Asymmetric Linkages between BRICS Stock Returns and Country Risk Ratings: Evidence from Dynamic Panel Threshold Models. Review of International Economics, 24(1), 1-19.

Momin, E., \& Masih, A. (2015). Do US policy uncertainty, leveraging costs and global risk aversion impact emerging market equities? An application of bounds testing approach to the BRICS. MPRA Working Paper No. 65834.

Mumtaz, H., \& Surico, P. (2013). Policy Uncertainty and Aggregate Fluctuations. Queen Mary University of London, School of Economics and Finance, Working Paper No. 708.

Mumtaz, H., \& Theodoridis, K. (2015). Common and Country Specific Economic Uncertainty. Queen Mary University of London, School of Economics and Finance, Working Paper No. No. 752.

Mumtaz, H., \& Theodoridis, K. (Forthcoming). The Changing Transmission of Uncertainty shocks in the US: An Empirical Analysis. Journal of Business and Economic Statistics.

Mumtaz, H., \& Zanetti, F. (2013). The impact of the volatility of monetary policy shocks. Journal of Money, Credit and Banking, 45(4), 535-558.

Rapach, D. E., \& Zhou, G. (2013). Forecasting stock returns. Handbook of Economic Forecasting, 2(Part A), Graham Elliott and Allan Timmermann (Eds.), Amsterdam: Elsevier, 328-383.

Redl, C. (2015). Macroeconomic Uncertainty in South Africa. Economic Research Southern Africa, Working Paper No. 509.

Rossi, B., \& Sekhposyan, T. (2015). Macroeconomic uncertainty indices based on nowcast and forecast error distributions. The American Economic Review, 105(5), 650-655.

Rossi, B., Sekhposyan, T., \& Soupre, M. (2016). Understanding the Sources of Macroeconomic Uncertainty. Mimeo, Universitat Pompeu Fabra - Centre de Recerca en Economia Internacional (CREI).

Shin, M., \& Zhong, M. (2016). A New Approach to Identifying the Real Effects of Uncertainty Shocks. Finance and Economics Discussion Series 2016-040. Washington: Board of Governors of the Federal Reserve System.

Sims, C. A. (1980). Macroeconomics and Reality. Econometrica, 48(1), 1-48. 
Strobel, J. (2015). On the different approaches of measuring uncertainty shocks. Economics Letters, 134, 69-72.

Sum, V. (2012a). The Reaction of Stock Markets in the BRIC Countries to Economic Policy Uncertainty in the United States. SSRN Paper No. 2094697.

Sum, V. (2012b). How Do Stock Markets in China and Japan Respond to Economic Policy Uncertainty in the United States? SSRN Paper No. 2092346.

Sum, V. (Forthcoming). Economic policy uncertainty and stock market returns. International Review of Applied Financial Issues and Economics.

White, H., Kim, T.H., Manganelli, S. (2015). VAR for VaR: Measuring tail dependence using multivariate regression quantiles. Journal of Econometrics, 187, 169-188.

Wu, T-P., Liu, S-B., and Hsueh, S-J. (2016). The Causal Relationship between Economic Policy Uncertainty and Stock Market: A Panel Data Analysis. International Economic Journal, 30(1), 109-122.

Yang, M., \& Jiang, Z-Q. (2016). The dynamic correlation between policy uncertainty and stock market returns in China. Physica A: Statistical Mechanics and its Applications, 461, 92-100.

Yin, L. \& L. Han (2014). Spillovers of macroeconomic uncertainty among major economies. Applied Economics Letters 21: 938-944. 


\section{Appendix}

Table A1: Descriptive statistics

\begin{tabular}{lcccc}
\hline \hline & \multicolumn{4}{c}{ Mature Markets } \\
\cline { 2 - 5 } Mean & United States & Germany & France & United Kingdom \\
\cline { 2 - 5 } Stand.Dev & 0.0078 & 0.0081 & 0.0018 & 0.0035 \\
Skewness & -0.5447 & 0.6861 & 0.5405 & 0.6633 \\
Kurtosis & 7.5908 & -0.0740 & -0.0883 & -0.0296 \\
Max. & 4.7586 & 4.0349 & 5.6689 & 4.6936 \\
Min. & -4.1126 & -3.8542 & -4.0240 & -4.1346 \\
Jarque-Bera & $11535.82^{* *}$ & $3247.1 * *$ & $4349.9 * *$ & $6522.8^{* *}$ \\
\hline
\end{tabular}

\section{BRICS}

\begin{tabular}{lccccc} 
& Brazil & Russia & China & India & South Africa \\
\cline { 2 - 6 } Mean & 0.0367 & 0.0761 & 0.0342 & 0.0443 & 0.0201 \\
Stand.Dev & 1.5016 & 2.5631 & 1.9389 & 1.5373 & 1.7820 \\
Skewness & 0.2564 & 0.1893 & 0.2494 & -0.4352 & -0.3784 \\
Kurtosis & 10.2530 & 14.0049 & 6.1585 & 7.0345 & 4.7706 \\
Max. & 19.5269 & 27.5476 & 15.7124 & 15.0784 & 12.0958 \\
Min. & -10.4825 & -19.8503 & -13.5215 & -12.5930 & -13.8615 \\
Jarque-Bera & $20729.7 * * *$ & $38611.1 * * *$ & $7508.2^{* * *}$ & $9881.9 * * *$ & $4588.3 * * *$
\end{tabular}

\begin{tabular}{lrc}
\hline & \multicolumn{2}{c}{ Uncertainty Indexes } \\
\cline { 2 - 3 } Mean & EMU* & EPU* \\
\cline { 2 - 3 } Stand.Dev & 68.8859 & 97.9910 \\
Skewness & 107.1779 & 69.7295 \\
Kurtosis & 5.2591 & 2.0901 \\
Max. & 48.9999 & 7.8447 \\
Min. & 1811.3300 & 719.0700 \\
Jarque-Bera & 4.8000 & 3.3200 \\
& $52.2^{* * *}$ & $144.6^{* * *}$
\end{tabular}

Notes: $\overline{\text { *To compute the descriptive statistics of the uncertainty indexes we used the index reported during }}$ the transactions days in our sample of mature markets. *** Null of normality is rejected at $1 \%$ level of significance. 


\section{Stock Market's Reactions to Economic Policy Uncertainty (EPU)}

Table A2 reports the summary of the reduced-form models, estimated using the EPU index. For most of the markets, economic policy uncertainty is significant at the $1^{\text {st }}$ percentile, but not at the $99^{\text {th }}$ percentile, that is the case for the US, Germany, Brazil, China and South Africa. In some cases the situation is just the contrary, for instance, in the United Kingdom and Russia. France is the only market in which uncertainty is not significant at any tail. In terms of the median scenarios, we observe that uncertainty is always significant for the stock markets.

Table A2. Cross-dependence between stock returns and economic policy uncertainty at different quantiles.

\section{Mature Markets}

\begin{tabular}{lccccccccc}
\hline & \multicolumn{2}{c}{ United States } & \multicolumn{2}{c}{ Germany } & \multicolumn{2}{c}{ France } & \multicolumn{2}{c}{ United Kingdom } \\
\hline & statistic & p-value & statistic & p-value & statistic & p-value & statistic & p-value \\
\cline { 2 - 9 } 1st Percentile & 30.38 & $<0.001$ & 25.69 & $<0.001$ & 7.46 & 0.11 & 4.02 & 0.40 \\
50th Percentile & 101.98 & $<0.001$ & 67.23 & $<0.001$ & 109.34 & $<0.001$ & 103.79 & $<0.001$ \\
99th Percentile & 14.44 & 0.01 & 11.12 & 0.03 & 11.96 & 0.02 & 25.98 & $<0.001$ \\
\hline
\end{tabular}

\section{BRICS}

\begin{tabular}{|c|c|c|c|c|c|c|c|c|c|c|}
\hline & \multicolumn{2}{|c|}{ Brazil } & \multicolumn{2}{|c|}{ Russia } & \multicolumn{2}{|c|}{ China } & \multicolumn{2}{|c|}{ India } & \multicolumn{2}{|c|}{ South Africa } \\
\hline & statistic & p-value & statistic & p-value & statistic & p-value & Statistic & p-value & statistic & $\begin{array}{c}\mathrm{p}- \\
\text { value }\end{array}$ \\
\hline 1st Percentile & 39.12 & $<0.001$ & 3.61 & 0.46 & 36.44 & $<0.001$ & 44.71 & $<0.001$ & 23.06 & $<0.001$ \\
\hline 50th Percentile & 54.93 & $<0.001$ & 183.77 & $<0.001$ & 306.17 & $<0.001$ & 162.28 & $<0.001$ & 129.09 & $<0.001$ \\
\hline 99th Percentile & 1.92 & 0.75 & 20.99 & $<0.001$ & 13.14 & 0.01 & 23.18 & $<0.001$ & 8.90 & 0.06 \\
\hline
\end{tabular}

Note: the statistic reported for each market, tests whetherthe quantiles of the stock returns depend on the first lag of uncertainty and the first lag of the uncertainty's quantiles. That it, it tests the joint cross-dependency among the series, under the null of independency. The results are estimated at three different quantiles, the 1st, 50th, and 99th percentiles. 
We also report the results of the dynamic responses of each market, facing an EPU shock in Figures A1 and A2. According to the analysis of Table A2, in the case of mature markets, specifically for US and Germany, the EPU shock is (slightly) significant at the lower tail of the distribution, but not at the upper tail. For France and the United Kingdom, policy uncertainty does not produce significant effects on the stock returns, at any percentile. The effects on the median, although appeared to be significant following Table A2, produce dynamic responses in the stock markets statistically indistinguishable for zero.

Figure A1. Economic Policy Uncertainty Spillovers to Stock Markets Returns:

\section{Mature Markets}

\section{United States}
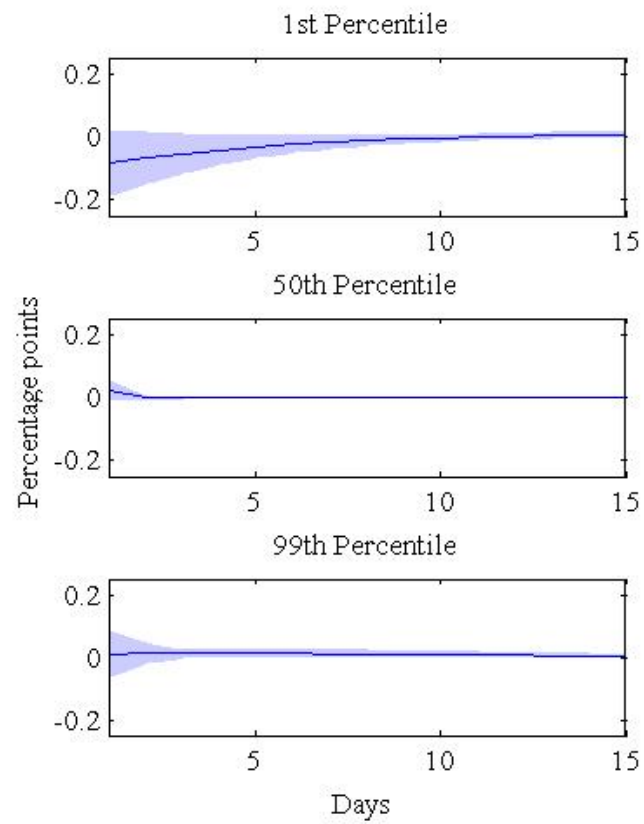

\section{Germany}
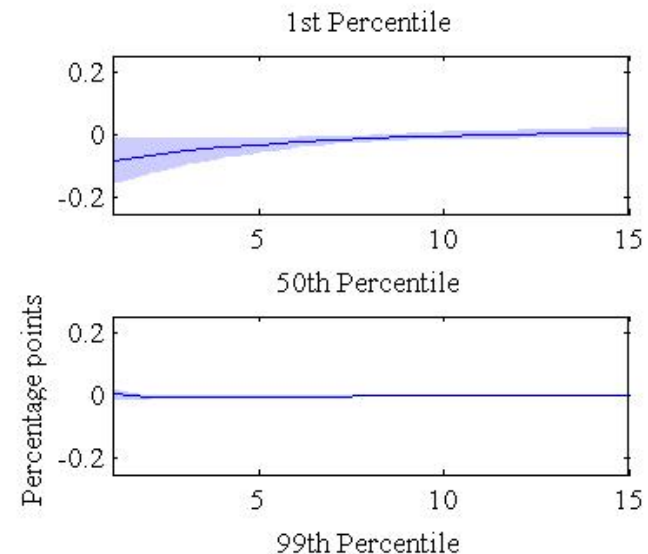

99th Percentile

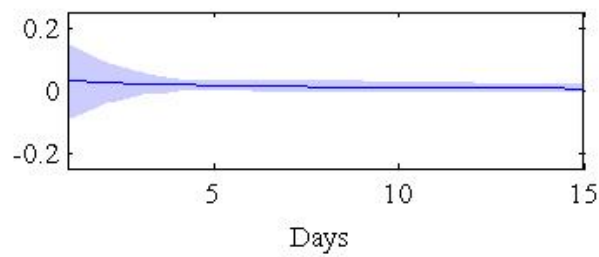


France
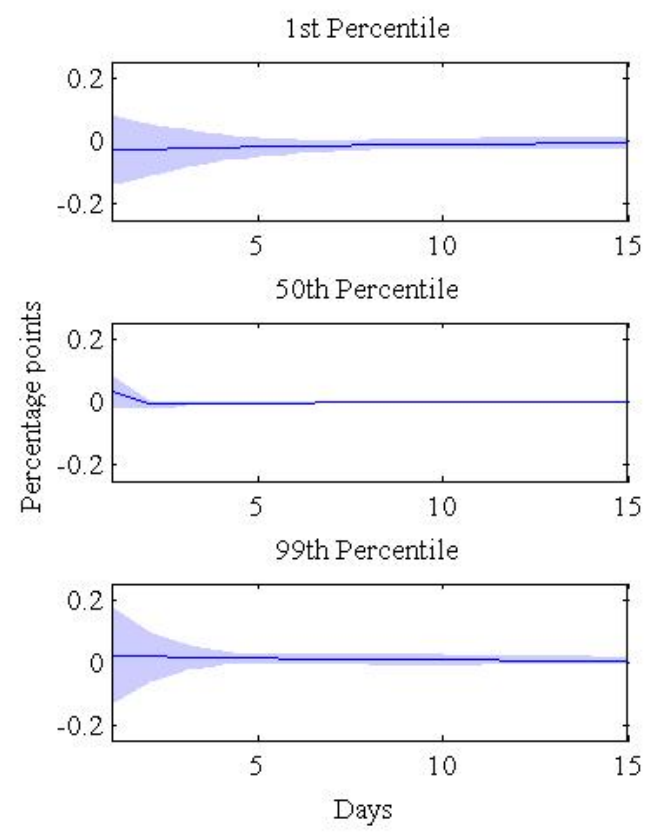

United Kingdom
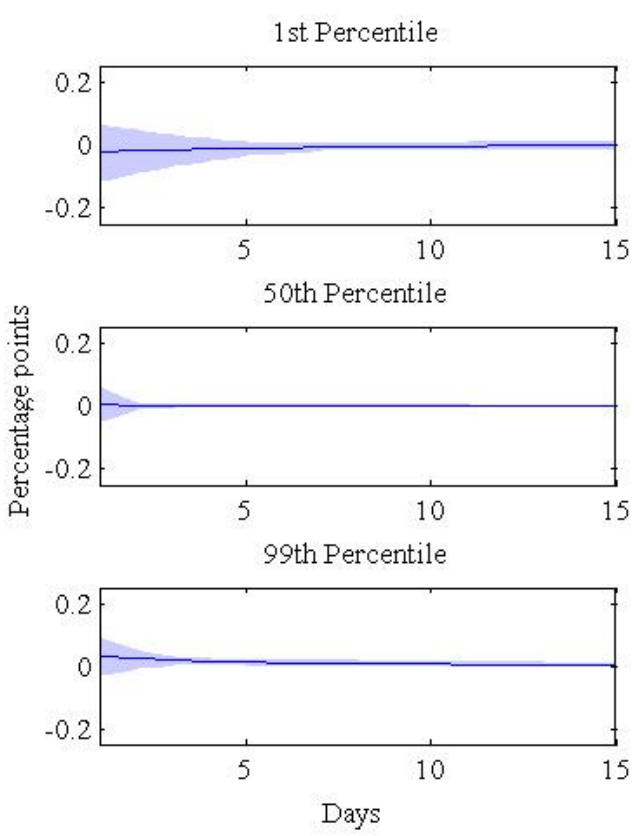

Note: The figure shows the pseudo quantile impulse response functions of the four mature markets in our sample, following an economic policy uncertainty shock in the US. The shock is equal to a one-standard deviation of the uncertainty index. The shadowed area is the 95\% asymptotic confidence interval provided by White et al. (2015). Each system is bivariate and it includes the EPU index in logs and the stock returns of each market, in percentage points.

In the case of the BRICS, we observe that for some markets, such as Brazil, India and South Africa, EPU induce a significant effect on the stock market returns, at the lowest percentiles, but insignificant at the highest. For China and Russia, the PQIRFs cover the zero during the horizon that we analyzed. Finally, the effects on the median are small, and they lack persistence. 
Figure A2. Economic Policy Uncertainty Spillovers to Stock Markets Returns:

\section{BRICS' Markets}

Brazil
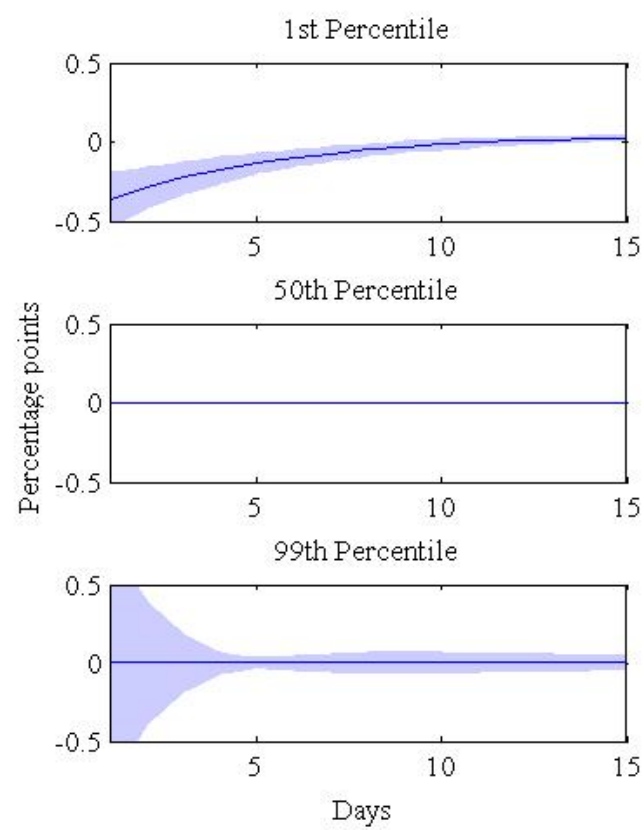

India
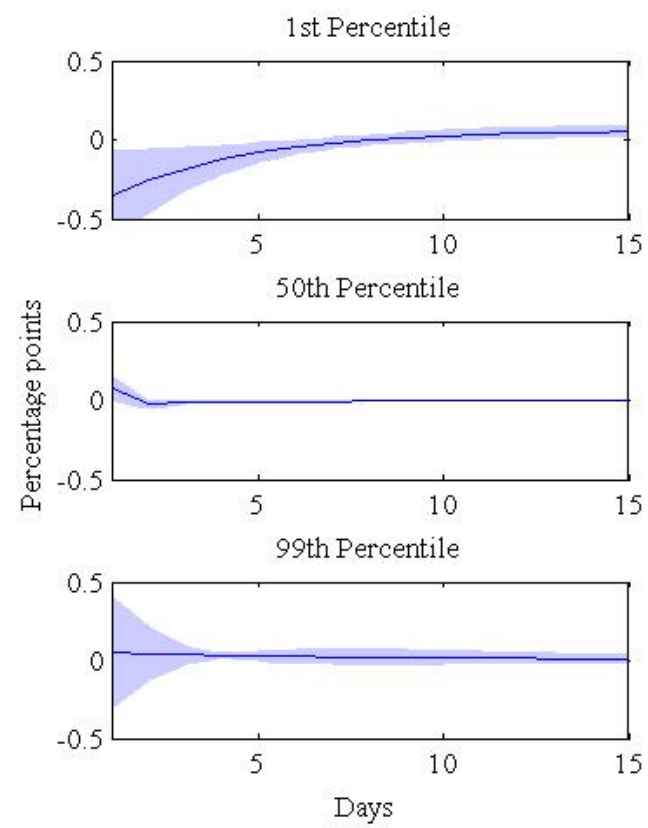

Russia
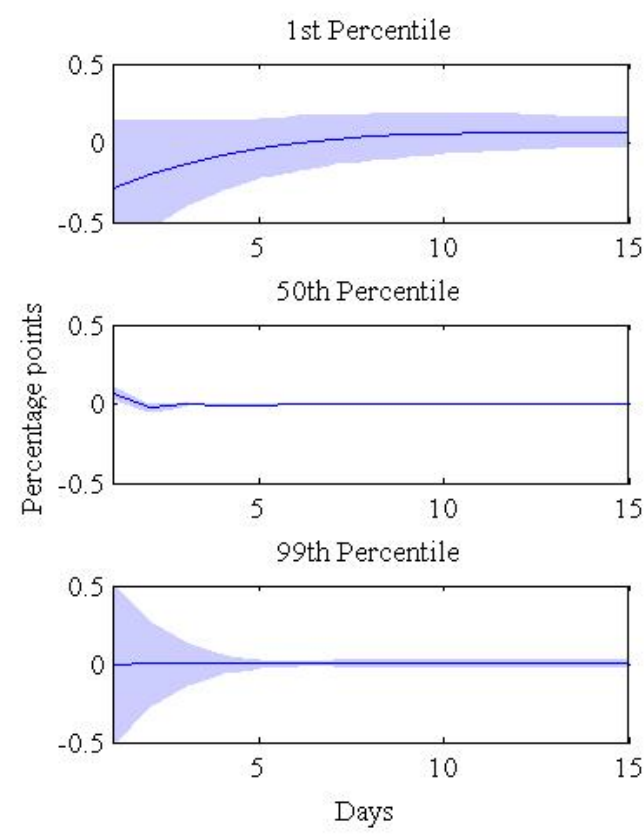

China
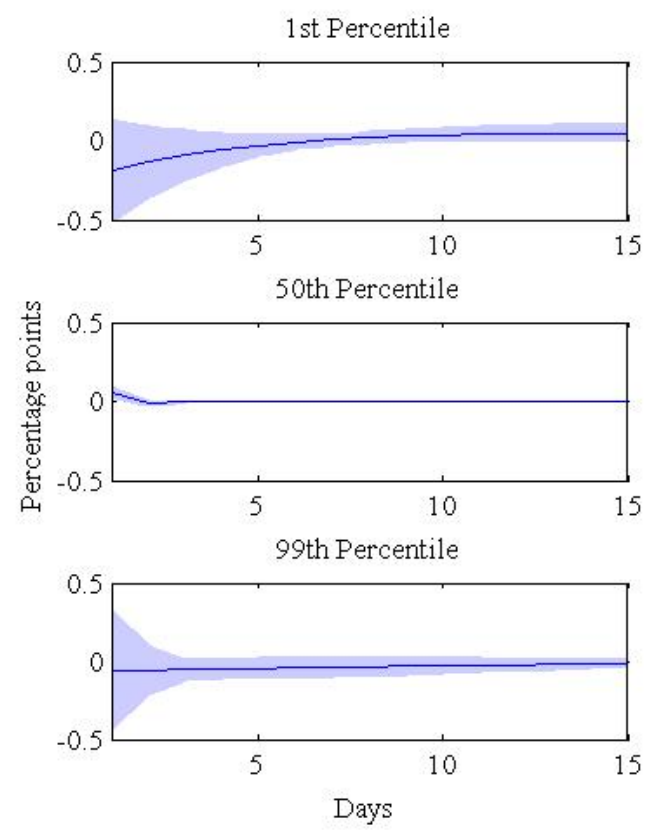


\section{South Africa}
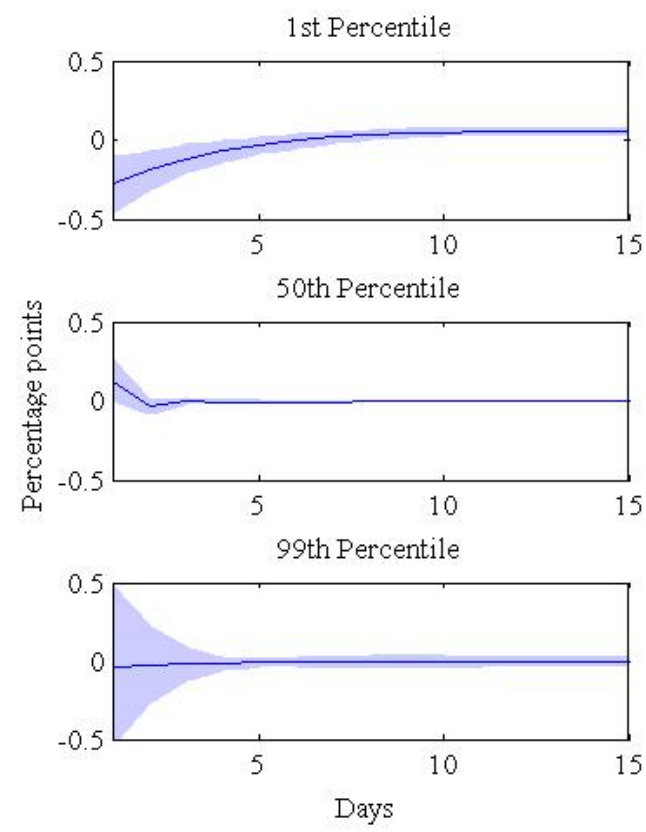

Note: The figure shows the pseudo quantile impulse response functions of the BRICS markets, following an equity market uncertainty shock in the US. The shock is equal to a one-standard deviation of the uncertainty index. The shadowed area is the $95 \%$ asymptotic confidence interval provided by White et al. (2015). Each system is bivariate and it includes the EPU index in logs and the stock returns of each market, in percentage points. 